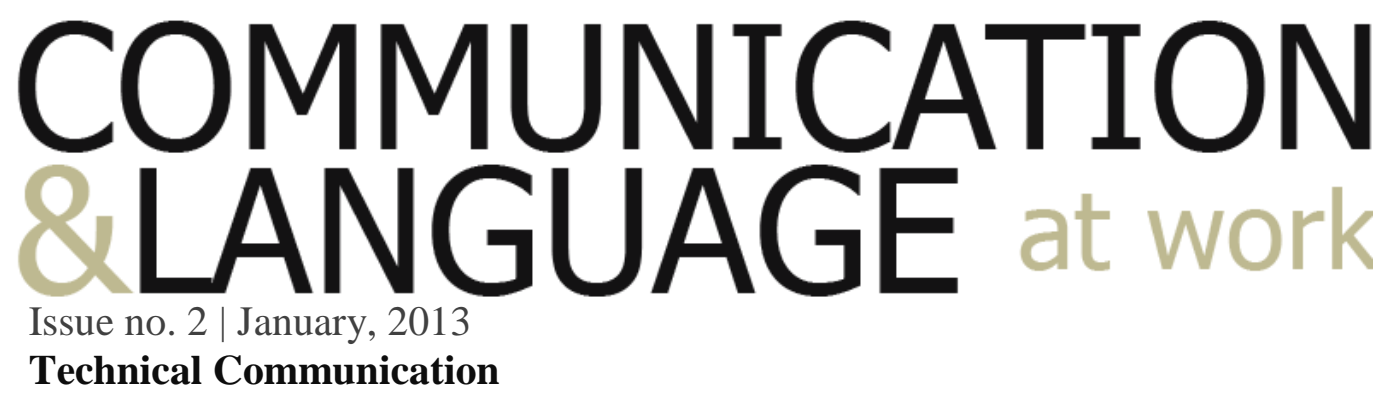

\title{
INTERVIEW: Quick, Social and Collaborative - Wiki-based user documentation at APC by Schneider Electric
}

Margrethe H. Møller interviews Pernille B. Nielsen \& Stanislav Kalianov

(pp. 60-63)

http://ojs.statsbiblioteket.dk/index.php/claw/article/view/7898

Subscribe:

http://ojs.statsbiblioteket.dk/index.php/claw/notification/subscribeMailList

Archives:

http://ojs.statsbiblioteket.dk/index.php/claw/issue/archive

\section{Publishing:}

http://ojs.statsbiblioteket.dk/index.php/claw/about/submissions\#onlineSubmissions

\section{Contact:}

http://ojs.statsbiblioteket.dk/index.php/claw/about/contact

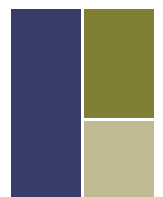

| Bridging Theory and Practice |

http://ojs.statsbiblioteket.dk/index.php/claw 


\title{
INTERVIEW: Quick, Social and Collaborative
}

\author{
Wiki-based user documentation at APC by Schneider Electric \\ Interview by Margrethe $\mathrm{H}$. Møller
}

\begin{abstract}
In the software documentation department at APC by Schneider Electric in Kolding, Denmark, Technical Writer Pernille Bagger Nielsen writes user documentation for the software developed by the company. In cooperation with Localization Manager Stanislav Kalianov she reorganised the user documentation for publication as wiki-based documentation on the internet. The new platform supports their strategy of using agile and iterative, topic-based, collaborative writing when developing user documentation. Their experience will interest readers who consider introducing a similar new strategy.
\end{abstract}

MøLLER: Your department has ported its user documentation to a wiki-based platform - what was the 'before' and 'after'?

PERNILLE: Before, we had a built-in context sensitive help system that was shipped with the software products. It was working really well for us except updates to the help

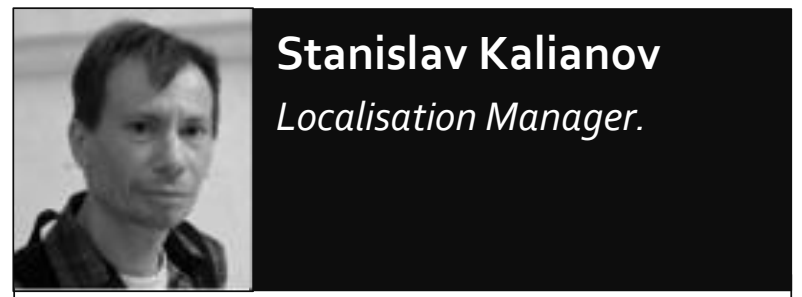

Responsible for managing outsourced localisation and product internationalisation in Schneider Electric IT Business

Previously: Localisation coordinator, Localisation engineer at McAfee Inc., Lionbridge Technologies Inc. and Apple Inc.

Education: Computer development and Asian languages. Through previous work, he specialises in localisation of software and instructional products. could not be implemented before a new version of the software was released since the help was built into the application. At the same time our agile development method means developing and changing features until the very last minute of a release but because we deliver the software with simultaneous

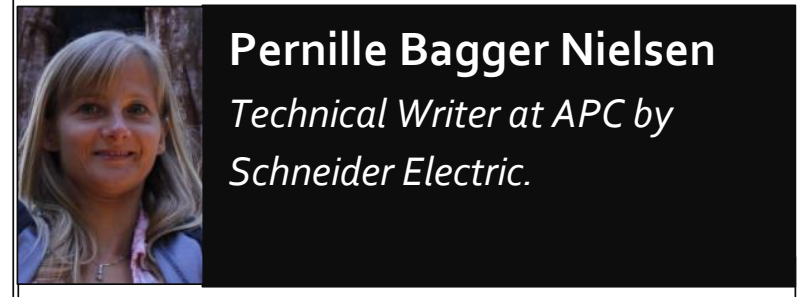

Previously: Translator and Technical Writer at Geac Runtime

Education: MA in French and Business Languages 


\section{C ommunication \& Language at Work}

translations, the deadline for finishing the user assistance still has to leave enough time for translation prior to a release. It was challenging to write about features that were not complete yet and put the pen down weeks before a release to meet the translation requirements. We always had changes that we wanted to implement after the translation deadline and even approaching or after release of the software.

The main reasons for looking for alternatives were the increasing localization costs and the need for quicker updates. The user assistance is now web-based and the wiki platform makes it possible to update the contents continuously independent of software releases. The translation deadline still imposes some of the same restrictions on the writer for simultaneous translations but the writing process is now prolonged to include the code-freeze phase where the software is tested and only bugs are fixed. Using analytics tools to monitor page visits, we can also postpone or cancel translations for pages and languages seldom used. In addition, the wiki platform allows user interaction and collaborative writing.

STANISLAV: What we also see now is that user assistance is updated even after the product release. Traditionally, customer questions would be answered in technical support articles or knowledge bases. Now, we have the ability to alter documentation to make important changes resulting from customer queries.

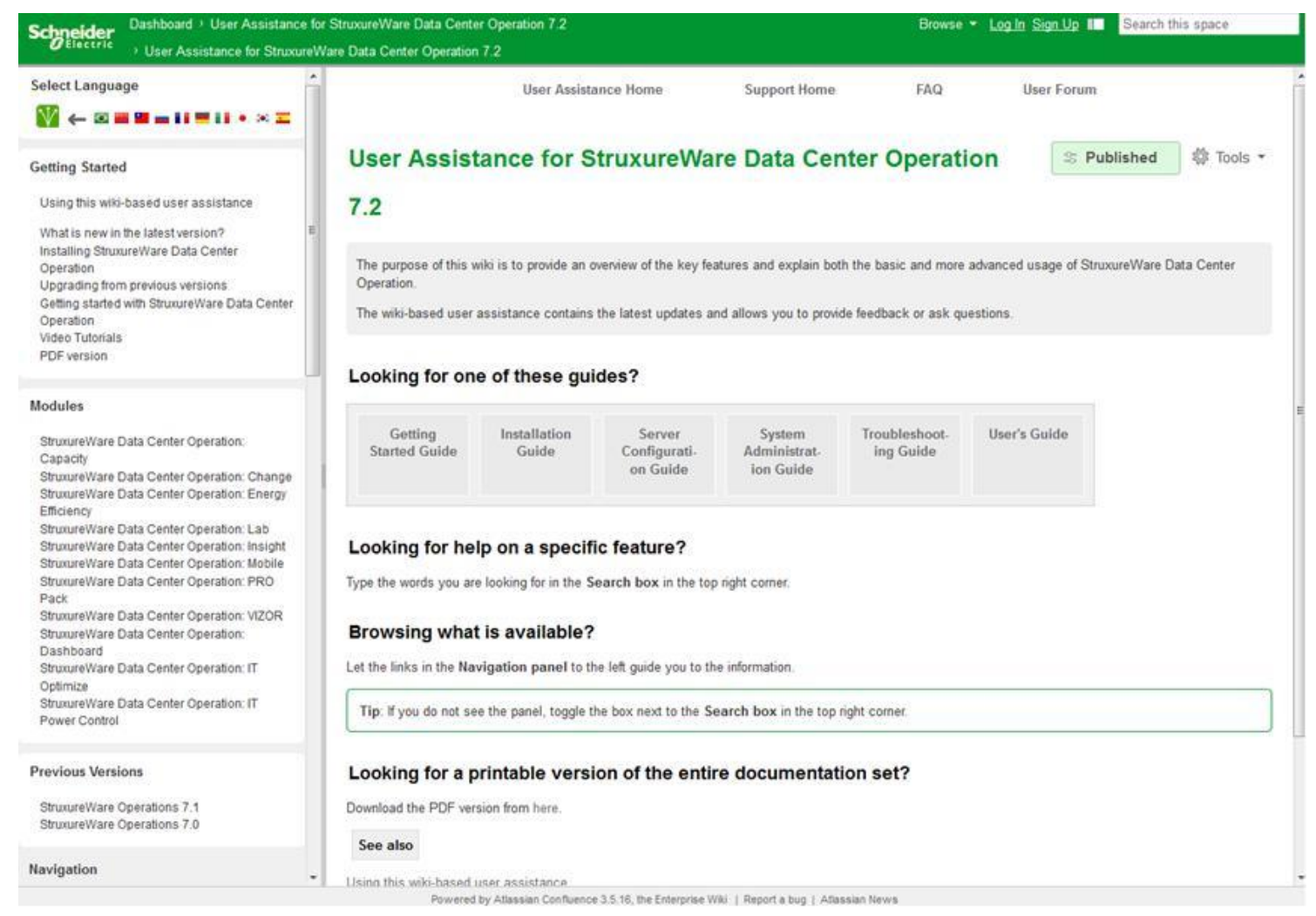

Figure 1: Wiki-based user documentation homepage 


\section{MøLLER: What advantages did you expect from this new platform?}

PERNILLE: We expected the new platform to:

- be quick, social and collaborative (collaborative writing with developers and other stakeholders);

- enable continuous revision;

- enable use of free and easy analytics tools to learn about usage of the user assistance and target the effort based on these findings; and

- have a model that is easily applied to other projects.

\section{MøLLER: What does the new documentation workflow look like?}

PERNILLE: Agile topic-based writing (iterative) is used when developing contents for the next releases. A draft version of wiki pages can be created by the Technical Writer or any member of the development team. All pages for a version are restricted to internal users until final approval by the Technical Writer, after which the status is changed to 'published' and the pages become publically available.

A workflow plug-in to our wiki tool helps control the status of the pages from draft to published.

Subsequently, when performing continuous updates to already released contents, this workflow also ensures that modified pages are shown only to internal users as long as they are being reviewed while, at the same time, the latest published version is shown to the public. This allows for collaborative writing by the entire development team and the Technical Writer still approves the contents before shown to the public.

MøLLER: Could you describe the process towards the new platform: who participated, were any organizational changes necessary, how was the new platform introduced within the organization, etc.?

PERNILLE: We did not need any organizational changes to make the switch to the new platform. The development team already used the wiki tool for internal knowledge sharing on projects so we were already familiar with the wiki. Localization Manager Stanislav Kalianov and I started investigating if this platform could be transferred into a multi-lingual customer-facing user assistance platform while our software service team investigated the wiki as a support platform. We did a pilot project and started migrating already existing contents. It was immediately made available internally to the entire team for feedback and ideas and the new collaborative writing and review process was introduced. In the next release of the software the link was made available for users to open the wiki from the help menu in the software. The dcimsupport.apc.com site is now the one and only entry point for customers whether they are looking for support or user assistance. 


\section{C ommunication \& Language at Work}

STANISLAV: There were some small changes on the technical side. We placed the dcimsupport.apc.com server in a special place on our corporate network where it is protected, yet accessible to anybody on the internet. We have also assigned a system administrator to help us manage this server, but this is taking a very small percentage of this person's time.

MøLLER: What have the reactions been - from your customers and from your colleagues who must supply content to the platform?

PERNILLE: The feedback has been positive. Especially the quick video tutorials have been popular. In addition internal feedback has increased now that the developers, support team and product management experience immediate updates based on their feedback. This clearly adds value to the product.

STANISLAV: We are collecting network access statistics for dcimsupport.apc.com and can clearly see the ever increasing usage since it was introduced. Even if the users are not voicing their support, we can see that they are coming back to this site.

\section{MøLLER: Are there any other interesting points which we did not cover?}

STANISLAV: It was briefly mentioned above, but it is very important from a ROI point. Because our user assistance is web based, we can use site analytical tools, designed for web pages. We can see how many readers we have, where they are coming from, how long they stay on a page and which areas of documentation are most used.

Since our new user assistance is entirely web-based, we could mix and match different media in our pages, very much like any modern web site could. We could, for example, include video tutorials as mentioned above. Also, we are using web forms and questionnaires to communicate with the customer. The limiting factor is accessibility from different platforms, including portable devices like mobile phones. 